\title{
Evaluation of decay data of radium-226 and its daughters
}

\author{
V. Chisté, M.M. Bé, and C. Dulieu \\ Laboratoire National Henri Becquerel, LNE - CEA/LNHB, CEA Saclay, 91191 Gif-sur-Yvette Cedex, France
}

\begin{abstract}
A nuclear data evaluation (half-lives, emission energies and probabilities) of the nuclides of the Ra-226 chain ending at $\mathrm{Pb}-210$ (not included) has been performed taking into account the new data available in the literature. The need for new absolute measurements of the decay parameters for some nuclides of the decay chain is also emphasized.
\end{abstract}

\section{Introduction}

Radium-226 and its daughters, which belong also to the Uranium-238 decay chain, is an important naturally occurring radioactive chain, often used for calibration of high resolution gamma-ray detectors (HPGe, Ge-Li and others) and present in environmental and building material samples. For these reasons, its study is part of the coordinated research program in progress led by the IAEA.

In the present work, an evaluation of the gamma and alpha emissions of each nuclide of the Ra-226 chain ending at $\mathrm{Pb}$ 210 (not included) was performed taking into account the new data available in the literature. Due to its importance, extensive measurements of the gamma-ray emission intensities were carried out over the past ten years (approximately eleven new measurements) while, at the same time, alpha emission intensity measurements were very scarce (for example, for the last Ra-226 evaluation, only two references were found in the literature).

Moreover, in order to preserve the consistency of the decay scheme, gamma transition probabilities have been recalculated taking into account new internal conversion coefficient tables, as well as beta transition, conversion electrons, Auger electrons and X-rays emission intensities. Good agreement between calculated X-ray intensities from the decay scheme data and the measured data may not necessarily confirm the consistency of this decay scheme.

This evaluation will try to treat any possible discrepancies and highlight any lack of studies. In a first step, parent and daughters ending at $\mathrm{Pb}-210$ (not included) are given in radioactive equilibrium and in a second step we will continue this evaluation ending at $\mathrm{Pb}-206$, the stable nuclide at the end of the Ra-226 decay chain.

This evaluation was conducted following the rules established by the Decay Data Evaluation Project (DDEP) which can be found in [1].

\section{Evaluation}

The natural radioactive Ra-226 decay chain includes 13 nuclides, ending at the stable isotope of $\mathrm{Pb}-206$. In this work, the evaluation of gamma and alpha emissions were performed

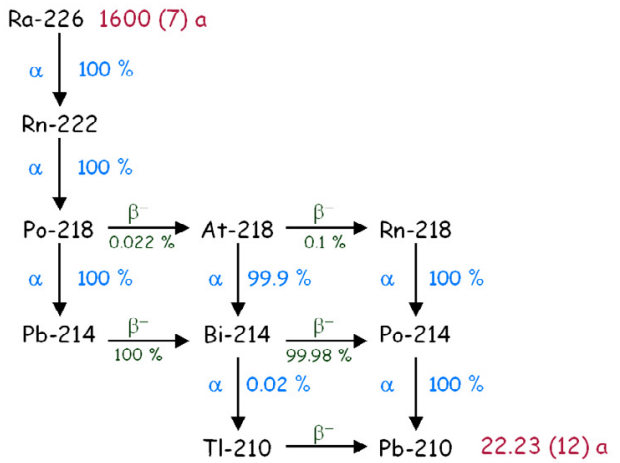

Fig. 1. Decay chain of Ra-226 evaluated in this work.

for 10 nuclides, from $\mathrm{Ra}-226$ ending at $\mathrm{Pb}-210$ as shown in figure 1.

\subsection{Half-lives}

The recommended half-lives and their uncertainties are the weighted means of the data sets found in the literature, calculated using the LWEIGHT computer code (table 1). In the case of $\mathrm{Pb}-214$ and $\mathrm{Bi}-214$, the recommended values presented in table 1 are the unique measurements found in the literature for each one, i.e., 26.8 (9) $\mathrm{min}$ for $\mathrm{Pb}-214$ given by M. Curie [2] in 1931 and 19.9 (4) min for $\mathrm{Bi}-214$ given by H. Daniel in 1956 [3].

The first eight daughter-nuclei of the main chain (Rn-222, Po-218, At-218, Rn-218, Pb-214, Bi-214, Po-214 and Tl-210) are very short-lived compared with Ra-226 and $\mathrm{Pb}-210$ so that radioactive equilibrium is quickly achieved (about one month). The recommended decay data and schemes of Ra-226 and its eight daughters will be published by LNHB (available at http://www.nucleide.org/NucData.htm) as individual nuclides along with the complete decay scheme.

\section{Gamma emission intensities}

In this evaluation, all experimental values of relative and absolute emission intensity used were measured for Ra-226 
Table 1. Recommended half-life values for the daughter nuclides of Ra-226.

\begin{tabular}{ll}
\hline $\mathrm{Ra}-226$ & $1600(7) \mathrm{a}$ \\
$\mathrm{Rn}-222$ & $3.8232(8) \mathrm{d}$ \\
$\mathrm{Po}-218$ & $3.094(6) \mathrm{min}$ \\
$\mathrm{At}-218$ & $1.4(2) \mathrm{s}$ \\
$\mathrm{Rn}-218$ & $36.0(19) \mathrm{ms}$ \\
$\mathrm{Pb}-214$ & $26.8(9) \mathrm{min}$ \\
$\mathrm{Bi}-214$ & $19.9(4) \mathrm{min}$ \\
$\mathrm{Po}-214$ & $162.3(12) \mu \mathrm{s}$ \\
$\mathrm{Tl}-210$ & $1.30(3) \mathrm{min}$ \\
$\mathrm{Pb}-210$ & $22.23(12) \mathrm{a}$ \\
\hline
\end{tabular}

and its daughters in equilibrium. For the nine nuclides evaluated, eighteen data sets were available in the literature, distributed between thirteen experimental values of relative emission intensity and five experimental values of absolute emission intensity. To take into account the experimental values of relative emission intensity, they were normalized using the absolute value of $609 \mathrm{keV}$ gamma-ray of Po- 214 .

\subsection{Absolute emission intensity of the 609-keV gamma-ray}

The absolute value of $609 \mathrm{keV}$ gamma-ray present in $\mathrm{Bi}-214$ disintegration to Po-214 is used to normalise the relative gamma-ray emission probabilities to absolute values in the Ra-226 decay chain. This gamma-ray is emitted from the $609 \mathrm{keV}$ level of spin $2+$ in Po-214, which is populated by beta decay from Bi-214 and many gamma-ray transitions of high energy levels. This level depopulates by one gamma-ray transition to the ground state level.

In table 2, the experimental values of $609 \mathrm{keV}$ gammaray absolute emission intensity found in the literature, dating from 1969 to 2004, are shown. The recommended value was calculated by taking the weighted mean of the five values listed in this table.

Table 2. Absolute emission intensity of the $609 \mathrm{keV}$ gamma-ray of Po-214 (in \%)

\begin{tabular}{ll}
\hline References & $\mathrm{P}_{\gamma}$ \\
\hline E.W.A. Lingeman (1969) [4] & $42.8(40)$ \\
D.G. Olson (1983) [5] & $45.0(7)$ \\
U. Schötzig (1983) [6] & $44.6(5)$ \\
W.-J. Lin (1991) [7] & $46.1(5)$ \\
J. Morel (2004) [8] & $45.57(18)$ \\
Evaluated value & $45.49(19), \chi^{2}=1.45$ \\
\hline
\end{tabular}

\subsection{Emission and transition probabilities of the major gamma-rays}

The recommended values for the relative gamma-ray emission intensities are the weighted means of the data sets found in the literature dating from 1969 to 2004 [4-18], calculated using the LWEIGHT computer code [19]. When necessary the uncertainties quoted by the authors were increased to achieve
Table 3. Main gamma-ray lines of Ra-226 decay chain in radioactive equilibrium with its daughters.

\begin{tabular}{|c|c|c|c|}
\hline Daughter & Energy (keV) & $\begin{array}{l}\text { Relative } \\
\text { Emission } \\
\text { Intensity }(\%)\end{array}$ & $\begin{array}{l}\text { Absolute } \\
\text { Emission } \\
\text { Intensity }(\%)\end{array}$ \\
\hline Rn-222 & $186.211(13)$ & $7.815(25)$ & $3.555(11)$ \\
\hline $\mathrm{Bi}-214$ & $\begin{array}{l}53.2275(21) \\
241.997(3) \\
295.224(2) \\
351.932(2) \\
785.96(9)\end{array}$ & $\begin{array}{l}2.331(16) \\
15.997(48) \\
40.48(8) \\
78.26(16) \\
2.339(28)\end{array}$ & $\begin{array}{l}1.060(9) \\
7.268(37) \\
18.414(36) \\
35.60(17) \\
1.064(13)\end{array}$ \\
\hline Po-214 & $\begin{array}{l}609.312(7) \\
665.453(22) \\
768.356(10) \\
806.174(18) \\
934.061(12) \\
1120.287(10) \\
1155.19(2) \\
1238.111(12) \\
1280.96(2) \\
1377.669(12) \\
1401.50(4) \\
1407.98(4) \\
1509.228(15) \\
1661.28(6) \\
1729.595(15) \\
1764.494(14) \\
1847.420(25) \\
2118.55(3) \\
2204.21(4) \\
2447.86(10)\end{array}$ & $\begin{array}{l}100 \\
3.364(15) \\
10.755(36) \\
2.774(13) \\
6.814(22) \\
32.77(7) \\
3.594(15) \\
12.819(29) \\
3.155(13) \\
8.722(25) \\
2.923(16) \\
5.252(17) \\
4.679(21) \\
2.304(20) \\
6.251(22) \\
33.66(10) \\
4.451(26) \\
2.545(12) \\
10.80(6) \\
3.403(16)\end{array}$ & $\begin{array}{l}45.49(19) \\
1.530(7) \\
4.892(16) \\
1.262(6) \\
3.100(10) \\
14.91(3) \\
1.635(7) \\
5.831(13) \\
1.435(6) \\
3.968(11) \\
1.330(7) \\
2.389(8) \\
2.128(10) \\
1.048(9) \\
2.844(10) \\
15.31(5) \\
2.025(12) \\
1.158(5) \\
4.913(23) \\
1.548(7)\end{array}$ \\
\hline
\end{tabular}

weighted contributions from each measurement of less than $50 \%$. Evaluated energies, relative emission intensities and absolute emission probabilities normalized by the evaluators, using the normalization factor of 45.49 (19) (table 2), are listed in table 3. Only those gamma-rays with emission intensities for each decay product above $1 \%$ are considered in this paper.

The evaluators have omitted from their analysis the first four sets of values in reference [13 and therein] and used only the last one, because these values come from the same laboratory.

The transition probabilities for all gamma-rays were calculated using the absolute gamma-ray emission intensities and the relevant internal conversion coefficients (ICCs). The ICCs have been interpolated from theoretical values of I.M. Band et al. [20] using the BRICC package [21] (calculation for "hole").

For the gamma-rays of Bi-214 (following the beta minus disintegration of Po-214), the evaluators have chosen to adopt the internal conversion coefficients deduced from the Rösel tables [22] (calculated using Icc99v3a computer program - GETICC dialog), because these ICCs lead to a more consistent decay scheme. The ICCs set values of I.M. Band et al. [20] (hole taken into account) lead to an inconsistent decay scheme, where the sum of all beta transition probabilities would be $102 \%$. 
Table 4. Main decay probability of the Ra-226 decay chain.

\begin{tabular}{lll}
\hline $\begin{array}{l}\text { Nuclide and } \\
\text { decay mode }\end{array}$ & $\begin{array}{l}\text { Transition } \\
\text { Energy (keV) }\end{array}$ & Probability (\%) \\
\hline Ra-226, & $4870.54(25)$ & $94.038(40)$ \\
$\alpha$ disintegration & $4684(1)$ & $5.950(40)$ \\
Rn-222, & $5590.2(3)$ & $99.92(1)$ \\
$\alpha$ disintegration & & \\
Pb-214, & $1024(11)$ & $9.2(7)$ \\
$\beta^{\mathrm{t}}$ disintegration & $729(11)$ & $41.09(39)$ \\
& $672(11)$ & $46.52(37)$ \\
& $185(11)$ & $2.762(22)$ \\
Bi-214, & & \\
$\beta^{\mathrm{t}}$ disintegration & $3275(11)$ & $19.67(20)$ \\
& $1894(11)$ & $7.45(5)$ \\
& $1729(1)$ & $3.12(4)$ \\
& $1542(11)$ & $17.494(36)$ \\
& $1508(11)$ & $17.10(8)$ \\
& $1425(11)$ & $8.147(28)$ \\
& $1255(11)$ & $2.449(10)$ \\
& $1153(11)$ & $4.339(18)$ \\
& $1068(11)$ & $5.642(43)$ \\
& $824(11)$ & $2.76(6)$ \\
\hline disintegration & $7833.24(6)$ & $99.9895(7)$ \\
\hline & &
\end{tabular}

\section{Alpha and beta emission probabilities}

A knowledge of alpha and beta direct emission probabilities is important, but, for this decay chain, recent direct emission probability measurements cannot be found in the literature. The unique measurements found were those given, for example, by Walen [23,24], Bastin-Scoffier (without uncertainties) [25] and LaMont [31] for alpha probabilities or by Hiessberger [26], Weinzierl [27] and Walen [23] (without uncertainties) for beta probabilities.

For these reasons, the recommended values of alpha and beta emission probabilities for most of the nuclides in the Ra-226 chain (except for Po-218 [24]) were deduced from the gamma-ray transition probabilities balance at each level of the individual decay scheme and shown in table 4 .

\section{Comparison with X-ray measurements and determination of Q-values}

The recommended X-ray absolute intensities have been calculated from gamma-ray data and ICCs using the EMISSION computer code [28]. Some measurements of X-ray data were be found in the literature for Ra-226 [6, 17,29], Pb-214 [4,6] and $\mathrm{Bi}-214$ [6]. In the case of Ra-226 (table 5), the recommended data and de Pinho values [29] are significantly greater than those measured by Delgado [17] and Schötzig [6]. De Pinho [29] used a Ra-226 source from which the descendants were removed. Since then, Delgado [17] and Schötzig [6] have carried out measurements with sources in equilibrium with their daughters.

In table 6, the recommended values of the decay energies $\mathrm{Q}$ given by G. Audi tables [30] are compared with the effective $\mathrm{Q}$-values $\left(\mathrm{Q}_{\mathrm{eff}}\right)$ calculated from the decay scheme data.
Table 5. Experimental and recommended values of X-ray emission intensities.

\begin{tabular}{lllll}
\hline & $\begin{array}{l}\text { Delgado } \\
{[17]}\end{array}$ & $\begin{array}{l}\text { Schötzig } \\
{[6]}\end{array}$ & $\begin{array}{l}\text { De Pinho } \\
{[29]^{a}}\end{array}$ & $\begin{array}{l}\text { Recommended } \\
\text { values. }\end{array}$ \\
\hline $\mathrm{K} \alpha_{1}$ & $0.215(3)$ & & & $0.317(6)$ \\
$\mathrm{K} \alpha_{2}$ & $0.156(39)$ & & & $0.192(4)$ \\
$\mathrm{K} \alpha$ & $0.371(39)$ & $0.418(21)$ & & $0.509(7)$ \\
$\mathrm{K} \beta_{1}$ & $0.079(5)$ & & & $0.1098(25)$ \\
$\mathrm{K} \beta_{2}$ & $0.020(4)$ & & & $0.0351(10)$ \\
$\mathrm{K} \beta$ & $0.099(6)$ & $0.145(9)$ & & $0.1449(27)$ \\
$\mathrm{XK}$ & $0.47(4)$ & $0.563(23)$ & $0.693(26)$ & $0.654(8)$ \\
$\mathrm{XL}$ & & & $0.839(43)$ & $0.807(13)$ \\
\hline
\end{tabular}

a) Calculated with $\mathrm{I} \gamma(186)=3.555(11)$, given by this evaluation.

Table 6. The recommended and calculated Q of reaction.

\begin{tabular}{llll}
\hline Nuclide & $\begin{array}{l}\text { Q given by } \\
\text { Audi [30] }(\mathrm{keV})\end{array}$ & Qeff $(\mathrm{keV})$ & $\begin{array}{l}\text { Relative error } \\
(\%)\end{array}$ \\
\hline Ra-226 & $4870.63(25)$ & $4870.5(27)$ & 0.00 \\
$\mathrm{Rn}-222$ & $5590.3(3)$ & $5590.1(6)$ & 0.01 \\
$\mathrm{Po}-218$ & $6114.68(9)$ & $6113.3(2)$ & 0.00 \\
$\mathrm{~Pb}-214$ & $1019(11)$ & $1024(11)^{b}$ & $0.51^{b}$ \\
& & $1029(15)^{c}$ & $0.99^{c}$ \\
$\mathrm{Bi}-214$ & $3270(11)$ & $3261(10)$ & 0.34 \\
Po-214 & $7833.46(6)$ & $7833.24(10)$ & 0.00 \\
\hline
\end{tabular}

b) ICC's given by Rösel [22].

c) ICC's given by Band (BRICC computer code) [20].

For Ra-226, Rn-222, Po-218 and Po-214, a good agreement was found between the recommended $\mathrm{Q}$ given by Audi [30] and the calculated values deduced from the decay scheme data. In the case of $\mathrm{Pb}-214$, the evaluators calculated Q eff taking into account the two sets of ICCs given by Rösel and by Band, respectively, and the better agreement was found with the Rösel ICCs.

\section{Conclusions}

The evaluation of a complex decay scheme, like this one, is a difficult exercise, requiring careful examination of all available data to ensure consistency throughout the assessment. All levels must be balanced and all observed gamma-rays need to be included in the decay scheme. For this reason, it is very important that all authors reporting decay data measurements provide well-defined uncertainties and all other relevant information needed by evaluators to make best use of their data.

For this evaluation, there was no difficulty finding new measurements for the gamma-ray emission intensities, however, the evaluators point out that new direct measurements are required for the alpha and beta emission probabilities (so far inexistent) as well as new measurements for half-lives. For example, for Pb-214 and Bi-214, the most critical cases, there haven't been any new measurements since 1931 and 1956 respectively. The situation is described in table 7, which contains a summary of the existing experimental data for the Ra-226 chain. 
Table 7. Summary of data set of the Ra-226 decay chain.

\begin{tabular}{|c|c|c|}
\hline Nuclide & $\begin{array}{l}\text { Type of } \\
\text { data }\end{array}$ & Situation \\
\hline \multirow[t]{3}{*}{ Ra-226 } & $\alpha$ & Two measurements in 1963 and \\
\hline & X-rays & $2001[25,31]$. \\
\hline & Half-life & $\begin{array}{l}\text { Last measurement in } 2002 \text { [17]. } \\
\text { No recent measurements since } 1966 \text {. }\end{array}$ \\
\hline \multirow[t]{4}{*}{ Rn-222 } & $\alpha$ & Last measurements in 1958 [23]. \\
\hline & $\gamma$-rays & No direct measurements available. \\
\hline & X-rays & No direct measurements available. \\
\hline & Half-life & Last measurement in 2004. \\
\hline \multirow[t]{4}{*}{ Po-218 } & $\alpha$ & Last measurements in 1958 [23]. \\
\hline & $\beta$ & Last measurements in 1952 [26]. \\
\hline & X-rays & No direct measurements available. \\
\hline & Half-life & No recent measurements since 1986. \\
\hline \multirow[t]{4}{*}{ At-218 } & $\alpha$ & Last measurements in 1958 [23]. \\
\hline & $\beta$ & Last measurements in 1948. \\
\hline & X-rays & No direct measurements available. \\
\hline & Half-life & No recent measurements since 1989. \\
\hline \multirow[t]{3}{*}{ Rn-218 } & & No direct measurements available. \\
\hline & $\mathrm{X}$-rays & No direct measurements available. \\
\hline & Half-life & No recent measurements since 1971. \\
\hline \multirow[t]{4}{*}{$\mathrm{Pb}-214$} & $\beta$ & No direct measurements available. \\
\hline & X-rays & No recent measurements since \\
\hline & Half-life & $1983[6]$. \\
\hline & & $\begin{array}{l}\text { No recent measurements since } \\
1931[2] .\end{array}$ \\
\hline \multirow[t]{5}{*}{ Bi-214 } & $\alpha$ & Last measurements in 1960 [24]. \\
\hline & $\beta$ & No direct measurements available. \\
\hline & $\mathrm{X}$-rays & No recent measurements since 1983 \\
\hline & Half-life & {$[6]$.} \\
\hline & & $\begin{array}{l}\text { No recent measurements since } \\
1956[3] \text {. }\end{array}$ \\
\hline \multirow[t]{3}{*}{ Po-214 } & $\alpha$ & No direct measurements available. \\
\hline & $\mathrm{X}$-rays & No direct measurements available. \\
\hline & Half-life & No recent measurements since 1993. \\
\hline
\end{tabular}

\section{References}

1. Monographie BIPM-5 - Table of Radionuclides, Vol. 3, M.M. Bé, V. Chisté, C. Dulieu, (LNHB), France; E. Browne, C. Baglin, (LBNL), USA; V. Chechev, N. Kuzmenko, (KRI), Russia; R. Helmer, (INEEL), USA; F. Kondev, (ANL), USA; T. Desmond MacMahon, (NPL), UK; K.B. Lee (KRISS), South Korea Table of Radionuclides, Monographie BIPM-5, ISSN 92-822-2204-7 (set), ISBN 92-822-2218-7 (Vol. 3) and ISBN 92-822-2219-5 (CD), CEA/LNE-LNHB, 91191 Gif-surYvette, France and BIPM, Pavillon de Breteuil, 92312 Sèvres, France.

2. M. Curie, A. Debierne, A.S. Eve, H. Geiger, O. Hahn, S.C. Lind, St. Meyer, E. Rutherford, E. Schweildler, Rev. Mod. Phys. 3, 427 (1931).

3. H. Daniel, Z. Naturforsch. 11a, 212 (1956).
4. E.W.A. Lingeman, J. Konijn, P. Polak, A.H. Wapstra, Nucl. Phys. A 133, 630 (1969).

5. D.G. Olson, Nucl. Instrum. Meth. 206, 313 (1983).

6. U. Schötzig, K. Debertin, Int. J. Appl. Radiat. Isotop. 34, 533 (1983).

7. W.-J. Lin, G. Harbottle, J. Radioanal. Nucl. Chem. Lett. 153, 137 (1991).

8. J. Morel, S. Speman, M. Rasko, E. Terechtchenko, J.U. Delgado, Appl. Radiat. Isotop. 60, 341 (2004).

9. K.Ya. Gromov, B.M. Sabirov, J.J. Urbanets, Bull. Acad. Sci. USSR, Phys. Ser. 33, 1510 (1969).

10. G. Wallace, G.E. Coote, Nucl. Instrum. Meth. 74, 353 (1969).

11. R.S. Mowatt, Can. J. Phys. 48, 2606 (1970).

12. V.S. Aleksandrov, JINR - PL 7308 (1973).

13. A. Hachem, Compt. Rend. (Paris) 281B, 45 (1975); G. Mouze, Compt. Rend. (Paris) 292, 1243 (1981); H. Akcay, G. Mouze, D. Maillard, C. Ythier, Radiochem. Radioanal. Lett. 51, 1 (1982); O. Diallo, G. Mouze, C. Ythier, J.F. Comanducci, Nouvo Cimento 106A, 1321 (1993); G. Mouze, C. Ythier, J.F. Commanducci, Rev. Roumaine Phys. 35, 337 (1990).

14. V. Zobel, J. Eberth, U. Eberth, E. Eube, Nucl. Instrum. Meth. 141, 329 (1977).

15. M.A. Farouk, A.M. Al-Soraya, Nucl. Instrum. Meth. 200, 593 (1982).

16. D. Sardari, T.D. MacMahon, J. Radioanal. Nucl. Chem. 244, 463 (2000).

17. J.U. Delgado, J. Morel, M. Etcheverry, Appl. Radiat. Isotop. 56, 137 (2002).

18. G.L. Molnar, Z.S. Révay, T. Belgya, in Proceedings of $11^{\text {th }}$ Int. Symp. on capture gamma-ray spectroscopy, 2-6 Sept. 2002, (Pruhonice, 2003), p. 522.

19. W.L. Zipj, Report ECN FYS/RASA - 85/19, 1985.

20. I.M. Band, M.B. Trzhaskovskaya, C.W. Nestor Jr., P.O. Tikkanen, S. Raman, At. Data Nucl. Data Tables 81, 1 (2002).

21. T. Kibedi, T.W. Burrows, M.B. Trzhaskovskaya, C.W. Nestor Jr., in Proceedings Intern. Conf. Nuclear Data for Science and Technology, Santa Fe, New Mexico, 2004, Vol. 1, edited by R.C. Haight, M.B. Chadwick, T. Kawano, P. Talou, (2005) p. 268; AIP Conf. Proc. 769 (2005).

22. F. Rösel et al., At. Data Nucl. Data Tables 21, 91 (1978).

23. R.J. Walen, G. Bastin, Proceedings of International Nuclear Physics Conference, Paris, 1959, p. 910.

24. R.J. Walen, G. Bastin-Scoffier, Nucl. Phys. 16, 246 (1960).

25. G. Bastin-Scoffier, C.F. Leang, R.J. Walen, J. Phys. 24, 854 (1963).

26. F. Hiessberger, B. Karlik, Stizber. Akad. Wiss., Wien, Math.Naturw. Kl. Abt. IIa 161, 51 (1952).

27. P. Weinzierl, E. Ujlaki, G. Preinreich, G. Eder, Phys. Rev. 134, B257 (1964).

28. E. Schönfeld, H. Jan $\beta$ en, Appl. Radiat. Isotop. 52, 595 (2000).

29. A.G. de Pinho, M. Weskler, Z. Naturforsch 28a, 1635 (1975).

30. G. Audi, A.H. Wapstra, C. Thibault, Nucl. Phys. A 729, 129 (2003).

31. S.P. Lamont, R.J. Gehrke, S.E. Glover, R.H. Filby, J. Radioanal. Nucl. Chem. 248, 247 (2001). 